\title{
The Molecular Genetics of Human Sleep
}

\author{
Luoying Zhang ${ }^{1}$ and DR. Ying-Hui Fu, ${ }^{2}$, \\ ${ }^{1}$ Key Laboratory of Molecular Biophysics of Ministry of Education, College of Life Science and \\ Technology and the Collaborative Innovation Center for Brain Science, Huazhong University of \\ Science and Technology, Wuhan, Hubei 430074, China \\ ${ }^{2}$ Department of Neurology, University of California, San Francisco, CA 94143, USA
}

\begin{abstract}
It has been known for many years that genetic influences account for some of the individual differences in human sleep parameters, but the underlying molecular mechanisms remain unclear. With major advances of molecular biology and the recognition of heritable sleep behaviors in humans over the past 30 years, a number of genetic variants have been identified to be associated with human sleep timing, duration and quality, both in healthy individuals and under pathological conditions. Some of these variants were further validated and characterized in animal models, shedding light on the mechanism of how these variants likely alter sleep in humans, which may provide new insights for developing more effective treatments to improve human sleep.
\end{abstract}

\section{Abstract}

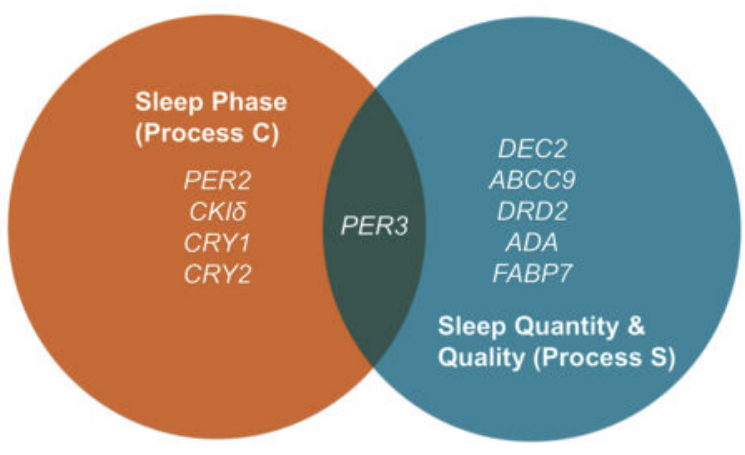

\section{Keywords}

genetic variant; sleep phase; sleep homeostasis; sleep disorders; animal model

Sleep is a fundamental process of life, and sleep deprivation or restriction can have severe health consequences(Mukherjee et al., 2015). A widely accepted working hypothesis regarding the regulation of sleep posits that sleep is controlled by two processes, termed

“Correspondence: ying-hui.fu@ucsf.edu.

Author Contributions

LZ and Y-HF wrote the manuscript.

The authors declare no conflict of interest. 
Process $\mathrm{C}$ and Process $\mathrm{S}$ (Borbely et al., 2016). Process $\mathrm{C}$ is driven by the circadian pacemaker and reflects changes in sleep propensity throughout the day. It restricts sleep to a certain time of the day. Process S, on the other hand, represents sleep debt, which accumulates during wakefulness and is discharged during sleep. It is reflected in the quantity (duration) and quality of sleep. Process $\mathrm{C}$ and Process $\mathrm{S}$ interact to regulate sleep, and defects in these processes can lead to sleep disorders(Cirelli, 2009; Borbely et al., 2016).

Studies conducted in the 1930s first reported a genetic influence on sleep by demonstrating a higher concordance of sleep parameters between monozygotic twins compared to dizygotic twins(Dauvilliers et al., 2005). In 1992, Medori et al identified a mutation in the prion protein that is believed to lead to fatal familial insomnia, and the PRNP gene encoding the prion protein is the first gene to be linked to human sleep disorder(Medori et al., 1992). Since then, mutations or variants in a number of genes have been linked to sleep. For some of these genetic variants, a causal relationship has been established with sleep, whereas for others, only correlations have been demonstrated. In this chapter, we will focus on the former and provide an overview of the variants identified to date, how their effects on sleep have been validated in animal models, and the molecular mechanisms responsible for these effects.

\section{Advanced and Delayed Sleep Phase}

Process $\mathrm{C}$ plays a major role in determining sleep time; thus, alterations in this process should lead to abnormal sleep time. This has indeed been observed in human individuals. The genetic basis for this phenomenon was first reported by Jones and colleagues, who found three "morning lark" family members with sleep onset and offset times that occurred 3-4 hours (h) earlier than those in normal subjects but in whom sleep duration did not differ from that of controls(Jones et al., 1999). This was accompanied by profound advances in other markers of circadian rhythms such as time of dim light melatonin onset and body temperature nadir. Moreover, the proband in the study by Jones et al. showed a shortened sleep/wake period and body temperature rhythms at least $\sim 1 \mathrm{~h}$ shorter than those of normal individuals, indicating altered timing of the circadian clock. The trait is inherited in an autosomal dominant manner and referred to as familial advanced sleep phase (FASP). The affected individuals were later found to carry a serine to glycine mutation within the casein kinase I (CKI)-binding region of the core clock protein PERIOD2 (PER2)(Toh et al., 2001). This results in hypophosphorylation of PER2 by CKI in vitro(Toh et al., 2001; Xu et al., 2007). Moreover, $\mathrm{Xu}$ and colleagues generated transgenic mice carrying the FASP variant (hPER2-S662G) and found that these animals exhibit phase-advanced wheel-running rhythms under light-dark cycles and a close to $2 \mathrm{~h}$ shorter period in constant darkness (DD) relative to hPER2-WT transgenic controls(Xu et al., 2007). The faithful recapitulation of the FASP phenotype in the mouse model confirms that PER2-S662G is indeed the causative variant, making it the first human variant identified to affect circadian rhythms. As a $\mathrm{S}$ to $\mathrm{G}$ mutation eliminates phosphorylation that may occur at this residue, the authors further generated transgenic mice carrying the PER2-S662D mutation, which mimics a constitutively phosphorylated state. In contrast, these animals showed almost a $1 \mathrm{~h}$ longer period. Taken together, these results indicate that phosphorylation at the S662 site is critical for determining the sleep/wake period length. Consistently, a second variant, a missense 
mutation in the gene encoding CKI $(\mathrm{CKI} \delta$-T44A), was identified in another family with FASP(Xu et al., 2005). The mutant kinase demonstrates reduced activity in vitro, and transgenic mice carrying the mutated human gene show an $\sim 0.5 \mathrm{~h}$ shorter period of wheelrunning rhythm.

Almost serendipitously, the very first two FASP mutations identified are in fact directly connected at the molecular level. Xu and colleagues first characterized this in vitro by showing that phosphorylation at PER2-S662 promotes phosphorylation of an adjacent series of serine residues by CKI, possibly leading to modifications of PER2 function(Xu et al., 2007). Then they revealed genetic interaction between $P E R 2$ and $C K I \delta$ in vivo. Expressing hPER2-S662G alone shortens the circadian period of mice by $1.7 \mathrm{~h}$, whereas expressing hCKIठ alone does not alter the period. However, when the two transgenes are co-expressed, the period is shortened by $\sim 3 \mathrm{~h}$, indicating that PER2-S662G and CKI $\delta$ act in synergy to determine period length. In contrast, expressing hPER2-S662D lengthens the period in mice by $0.8 \mathrm{~h}$, while knocking out a copy of the endogenous $C K I \delta\left(C K I \delta^{+/-}\right)$does not alter the period. When hPER2-S662D is expressed in $C K I \delta^{+/-}$animals, the period is lengthened by over $2 \mathrm{~h}$, once again indicating a synergistic interaction. Based on these results, the authors proposed that CKIס phosphorylates PER2, leading to alterations in PER2 function, which in turn affects the timing of the circadian clock.

Two additional genetic variants have been reported to be linked to FASP. In one family, a mutation in the core clock gene CRYPTOCHROME 2(CRY2) was identified that results in an alanine to threonine replacement at amino acid residue 260 (A260T)(Hirano et al., 2016). Transgenic mice carrying hCRY2-A260T exhibit slightly advanced activity rhythm. While the behavioral period is not substantially altered in DD, the period of molecular oscillation is shortened by $1 \mathrm{~h}$ or more in peripheral tissues. The mutation leads to increased binding of CRY2 with FBXL3, an E3 ubiquitin ligase, which results in enhanced degradation of CRY2. In another family, FASP individuals carried two rare variants in the PER3 gene (PER3$P 415 A / H 417 R)$ (Zhang et al., 2016). These individuals also had high Beck Depression Index and Global Seasonality Scores, which means they quite likely had seasonal affective disorder (SAD). Interestingly, one individual exhibited ASP only in winter but not in summer. Transgenic mice carrying hPER3-P415A/H417R show an $\sim 4 \mathrm{~h}$ phase delay of wheel-running rhythms under short days ( $4 \mathrm{~h}$ light: $20 \mathrm{~h}$ dark cycles) compared to $\mathrm{h} P E R 3-$ $W T$ mice, but no difference is observed under regular days ( $12 \mathrm{~h}$ light: $12 \mathrm{~h}$ dark cycles). Circadian period is not significantly altered by the mutant transgene in $\mathrm{DD}$, but under constant light, the period of $\mathrm{h} P E R 3-P 415 A / H 417 R$ is longer by $\sim 0.7 \mathrm{~h}$, consistent with a delayed phase. These observations indicate that the PER 3 variants do alter the phase, and possibly the circadian clock, but why the direction of phase change in mice is opposite of that in human warrants further investigation.

Recently, a variation in $C R Y 1($ c. $1657+3 \mathrm{~A}>\mathrm{C}$ ) was reported to be associated with delayed sleep phase disorder (DSPD)(Patke et al., 2017). This was first found in a family with 6 affected individuals and later validated in another 6 unrelated families with an additional 38 affected subjects. Free-running rhythms were measured for the proband, and the period is only slightly lengthened while the amplitude is dampened compared to that of a control subject. In mouse cells expressing variant CRY1, the period of molecular oscillation is 
longer by $0.5 \mathrm{~h}$. The variant results in defective splicing and skipping of exon 11 (CRY1 $\Delta 11)$. CRY1 $\Delta 11$ protein demonstrates enhanced binding with CLOCK/BMAL1 proteins and increased transcriptional inhibition.

As we review this series of findings, it is fair to say that only in the case of PER2-S662G mutation was an animal model able to beautifully recapitulate corresponding human phenotypes, including both advanced phase under LD and a prominently shorter period under free-running condition. None of the other FASP variants led to substantial phase advances in animal models that were comparable to those in human subjects. One explanation for this discrepancy is that the PER2 mutation may impinge on the timing mechanism of the core clock, which is highly conserved in model organisms and does not rely much on external factors. The other FASP variants, on the other hand, may affect the input pathway of light and/or other entrainment signals. Thus, the effects of these variants may depend on environmental factors that are masked or restricted by laboratory conditions and assessment methods. Evidence supporting this notion includes the observation that the DSPD individual does not exhibit a sizable period difference relative to unaffected controls, suggesting that the timing mechanism of the core clock in these individuals is relatively intact. Mechanistic differences between the circadian systems of humans and model organisms could also contribute to the lack of a prominent phase phenotype. Another possibility is that additional genetic variants are present in humans that influence circadian rhythms together with the identified variants, but these were not accounted for in animal models. All in all, genetic variants do appear to participate in regulating the timing of human sleep, although the underlying mechanisms require more in-depth research.

\section{Sleep Quantity and Quality}

Human sleep quantity and quality are measured by electroencephalography (EEG) (Cirelli, 2009). Based on EEG patterns, sleep can be divided into two types, non-rapid eye movement (NREM) sleep characterized by slow waves and rapid eye movement (REM) sleep characterized by fast activities of low voltage. The most studied electrical activity is delta activity, which is oscillation with a frequency of less than $4.5 \mathrm{~Hz}$, also known as slow wave activity (SWA). SWA is believed to be a marker of sleep intensity and to reflect sleep need, or the actions of Process S. Greater SWA indicates a deeper sleep and a higher sleep need. Sleep quantity is assessed by measuring the duration of total sleep and its various phases, whereas measures of sleep quality include latency to sleep onset, number of brief awakenings after sleep onset and the amount of SWA.

A rare variant in the circadian clock gene $D E C 2(D E C 2-P 384 R)$ has been causatively linked to sleep quantity and quality(He et al., 2009). The variant was identified in a family, and carriers routinely sleep $\sim 1.5 \mathrm{~h}$ less than non-carriers. $\mathrm{h} D E C 2-P 384 R$ transgenic mice show increased wake and reduced NREM and REM sleep during the light phase, which is the rest phase. An increased number of NREM episodes and reduced duration of each episode are also observed in these animals during the light phase, indicating more fragmented sleep. To further investigate the effects of $D E C 2-P 384 R$ on sleep need, sleep deprivation was conducted and subsequent rebound sleep was monitored. $\mathrm{h} D E C 2-P 384 R$ mice show reduced rebound for both NREM and REM sleep, and also for slow wave sleep, which suggests that 
the sleep need is lower in $\mathrm{h} D E C 2-P 384 R$ animals. Taken together, these results demonstrate that the short sleep duration in these individuals is likely due to $D E C 2-P 384 R$ mutation. An independent study found another variant $D E C 2-Y 362 H$, which is within the same exon as $D E C 2-P 384 R$, to be associated with reduced sleep duration and increased resistance to sleep deprivation(Pellegrino et al., 2014). Both mutations affect the transcriptional repressor function of DEC2, resulting in reduced ability of mutant DEC2 to suppress CLOCK/ BMAL1-driven transcriptional activation(He et al., 2009; Pellegrino et al., 2014). On the other hand, another mutation, DEC2-P384G, does not affect sleep or response to sleep loss and has no effect on CLOCK/BMAL1-mediated transactivation. The hypocretin (hcrt) mRNA level is significantly increased in $\mathrm{h} D E C 2-P 384 R$ mice, and this gene encodes a precursor protein of a neuropeptide producing orexin and known to play a critical role in maintaining wakefulness(Hirano et al., 2018). Furthermore, treating these animals with an orexin receptor antagonist reverses the decrease in immobility time. These findings suggest that $D E C 2-P 384 R$ reduces sleep duration at least in part by modulating orexin.

A genome-wide association study (GWAS) in a European population revealed an intronic variant in the $A B C C 9$ gene that can explain $\sim 5 \%$ of the variation in sleep duration(Allebrandt et al., 2011). $A B C C 9$ encodes an ATP-sensitive potassium channel subunit (SUR2), and pan-neuronal knockdown of its Drosophila homolog leads to a reduction in sleep during the first $3 \mathrm{~h}$ of the night in fruit flies. Transcriptome analysis of these fly heads showed down-regulation of Rho genes and up-regulation of epidermal growth factor receptor (EGFR) genes, which have established roles for sleep consolidation in Drosophila and are associated with human sleep duration(Allebrandt et al., 2017).

We have discussed the role of PER3 in the timing of sleep phase earlier in this review. Based on a number of studies that focused on a 54-nucleotide variable number tandem repeat (VNTR) polymorphism in exon 18 of the PER3 gene, PER3 is also believed to participate in the determination of sleep need. Individuals who are homozygous for the 5-repeat allele $\left(P E R 3^{5 / 5}\right)$, which is the less frequent allele, exhibit shortened latency to fall asleep, increased time spent in SWS, and elevated SWA during NREM sleep compared to those homozygous for the 4-repeat allele ( $P E R 3^{4 / 4}$ ) (Viola et al., 2007). Moreover, the decrease in cognitive performance during sleep deprivation is enhanced in PER $3^{5 / 5}$ individuals, and increased SWS and SWA are observed in the subsequent recovery sleep(Viola et al., 2007; Goel et al., 2009). Because this VNTR is primate specific, to establish a causal link between this polymorphism and sleep, Hasan and colleagues replaced exon 18 of mouse Per3 with human exon 18 coding for either 4 repeats or 5 repeats(Hasan et al., 2014). Per $3^{5 / 5}$ and Per $3^{4 / 4}$ mice do not show substantial differences in baseline sleep, but during recovery sleep after sleep deprivation, significant increases in SWS and delta activity are observed in $P e r 3^{5 / 5}$ animals, validating a role for PER3 in regulating sleep need.

A large-scale candidate gene sequencing project reported a single nucleotide polymorphism (SNP) within intron 1 of dopamine receptor D2 (DRD2) to be significantly associated with self-reported sleep duration and suggestively associated with sleep latency determined by EEG(Cade et al., 2016). Consistently, work in mice revealed that activation of dopamine neurons in the ventral tegmental area promotes wakefulness via D2-like receptors(Oishi et 
al., 2017). Furthermore, the dopamine system is known to play critical roles in regulating the quantity and quality of sleep in multiple organisms(Cirelli, 2009).

A functional variant at codon 8 of adenosine deaminase $(A D A-D 8 N)$, which lowers enzyme activity by $20-30 \%$, is associated with the duration of SWS and intensity of SWA(Retey et al., 2005). Heterozygous individuals display fewer nocturnal awakenings, accompanied by increased baseline SWS duration as well as enhanced intensity of delta activity both under baseline conditions and recovery sleep after sleep deprivation(Retey et al., 2005; Bachmann et al., 2012). In addition, several markers of sleepiness are enhanced in heterozygous subjects(Bachmann et al., 2012). Although ADA has not been shown to directly regulate sleep in animal models, a role for the adenosine system in regulating sleep duration and delta intensity has been well characterized(Porkka-Heiskanen et al., 1997; Huang et al., 2005). Taken together, the research findings indicate that reduced enzymatic activity of ADA-D8N may lead to increased adenosine levels, which promotes SWS and delta activity in humans.

A SNP at amino acid position 61 of fatty acid-binding protein 7 (FABP7-T61M) correlates with fragmented sleep in humans, although total sleep duration is not altered(Gerstner et al., 2017). Fabp 7 knockout mice exhibit fragmented sleep that is most prominently observed during NREM sleep, while sleep duration is not altered. In addition, expression of FABP7$\mathrm{T} 61 \mathrm{M}$ in astrocyte-like glia fragments sleep in flies and reduces sleep duration in the day. These results indicate that FABP7 functions to maintain sleep state.

Research in model organisms has provided substantial insight into the molecular mechanisms of sleep regulation, which include genes involved in the circadian clock, neuronal excitability, neurotransmission and metabolism(Sehgal \& Mignot, 2011). Consistently, genes that have been confirmed to be involved in modulating sleep in humans also fall into these categories, implying conservation in the molecular basis of sleep throughout evolution. What's more, this demonstrates the power of using animal models such as mouse and Drosophila to understand the molecular mechanisms of sleep in human.

\section{Sleep Disorders}

As mentioned earlier in this review, the first genetic variant identified to be linked to sleep quantity is a point mutation at codon 178 of the $P R N P$ gene that results in a substitution of aspartic acid with asparagine, in conjunction with the methionine polymorphism at codon 129(Goldfarb et al., 1992; Medori et al., 1992). Individuals carrying this allele develop untreatable, progressive insomnia characterized by marked reduction or loss of sleep. This is accompanied by impairments in the autonomic and motor systems, eventually leading to death. The underlying pathology of the disease is atrophy of the anterior ventral and mediodorsal thalamic nuclei, as well as some other regions of the brain, caused by mutant PrP protein that is protease resistant.

Restless legs syndrome (RLS) is a common sensorimotor disorder characterized by unpleasant sensations in the legs during periods of rest that create an irresistible urge to move the legs, leading to sleep disruptions(Allen et al., 2003). Two SNPs, one in intron 1 
and one in intron 3 of nitric oxide synthase 1 (NOS1), are reported to be associated with RLS in the German population, and the SNP in intron 1 is overrepresented in patients with a positive family history of RLS in the Spanish population(Winkelmann et al., 2008; JimenezJimenez et al., 2015). Consistently, a role for NOS1 in modulating sleep has been found in animal models. Activation of NOS1-expressing neurons in the mouse cerebral cortex positively correlates with markers of sleep need, including NREM sleep duration and intensity of delta activity(Morairty et al., 2013). Conversely, Nos1 knockout mice display reduced NREM sleep duration and delta activity under baseline condition. During recovery sleep following sleep deprivation, $\mathrm{Nos}^{1^{-1}-}$ mice also demonstrate decreased delta activity. However, these animals are believed to be sleepier as they fall asleep more readily and have more NREM sleep during short naps. It is proposed that NOS1 translates sleep need into an up-regulation of delta activity.

Two GWAS studies revealed significant associations between RLS and intronic variants in the $B T B(P O Z)$-domain containing $9(B T B D 9)$ gene, particularly RLS with periodic limb movements during sleep(Stefansson et al., 2007; Winkelmann et al., 2007; Li et al., 2017). Moreover, one of these variants is associated with periodic limb movements in sleep without RLS and not associated with RLS without periodic limb movements(Stefansson et al., 2007). Iron deficiency has been implicated in RLS pathogenesis and serum ferritin levels were found to be decreased by $\sim 13 \%$ per risk allele of this variant. Immunohistochemical analysis characterized BTBD9 as a cytoplasmic protein that is expressed in circuits regulating motor, memory and emotion both in human and rodents(Freeman et al., 2012). It belongs to a family of substrate adaptors for the cullin-3 (Cul-3) class of E3 ubiquitin ligases and colocalizes with Cul-3 in both a human cell line and neurons in the fly brain. Overexpression of BTBD9 in human cells leads to lowered ferritin levels, possibly by decreasing the level of iron regulatory protein-2, which is known to inhibit ferritin translation. Btbd9 knockout mice exhibit increased motor activities and wake duration as well as reduced SWS duration(DeAndrade et al., 2012). This is accompanied by enhanced sensory perception especially during the rest phase, which can be reversed by injection of ropinirole, a dopamine agonist widely used to treat RLS. Indeed, BTBD9 is expressed in dopaminergic neurons of the substantia nigra and hypothalamus in rats(Freeman et al., 2012). In addition, $B t b d 9$ knockout mice demonstrate elevated serum iron concentrations, indicating disruption of iron metabolism(DeAndrade et al., 2012). Knocking out $\mathrm{d} B T B D 9$ or knocking down this gene pan-neuronally in flies leads to sleep fragmentation at night, characterized by increased sleep bout number, reduced sleep bout duration and increased wake after sleep onset(Freeman et al., 2012). Similar to human patients and the mouse BTBD9 model, $\mathrm{d} B T B D 9$ knockout flies also show enhanced locomotor activity levels, or so called motor "restlessness". The dopamine level is decreased in these flies, and knockdown of $\mathrm{d} B T B D 9$ specifically in dopaminergic neurons is sufficient to fragment sleep in flies. Feeding $\mathrm{d} B T B D 9$ knockout flies with the dopamine agonist Pramipexole, which is used clinically to treat RLS, rescues the sleep fragmentation phenotype. Taken together, the results of these studies strongly suggest that $B T B D 9$ is a genetic determinant of limb movements during sleep.

Narcolepsy is a neurologic disease characterized by involuntary and irresistible "sleep attacks" that can occur while talking, standing, walking, eating and driving(Veatch et al., 
2017). This excessive sleepiness is typically associated with cataplexy (sudden bilateral skeletal muscle weakness), which is often provoked by strong emotion and lasts no longer than a few minutes. This sleep disorder also occurs in dogs, and a mutation in the hypocretin (orexin) receptor 2 gene (Hcrtr2) is believed to be the cause(Lin et al., 1999). Hypocretin ( $h c r t$ ) knockout mice exhibit narcoleptic-like attacks during the active phase, accompanied by significantly reduced wake and increased REM sleep(Chemelli et al., 1999). Reduction in wake time is a result of shortened wake bout duration and more rapid cycling between sleep and wake, mimicking the sleep attacks in narcolepsy patients. Moreover, the anti-narcoleptic drug Modafinil activates orexin neurons. In human patients, however, there is little evidence that variants in $H C R T$ or related genes contribute to narcolepsy(Veatch et al., 2017). Instead, narcolepsy with cataplexy is tightly associated with HLA class II allele $D Q B 1 * 0602$ (Tafti et al., 2016). $H L A$ genes encode major histocompatibility complex class II receptors, which are involved in the presentation of foreign peptides to T-cell receptors; therefore, it has been hypothesized that narcolepsy is caused by autoimmune attack of orexin neurons(Veatch et al., 2017). The $D Q B 1 * 0602$ allele confers an extraordinary risk for narcolepsy with cataplexy, while several other $D Q B 1$ alleles exert protective effects. Together this locus is believed to explain most of the risk and protection in narcolepsy with cataplexy(Tafti et al., 2014).

Some of the genetic alterations associated with sleep disorders appear to have pleiotropic effects, such as in the case of fatal familial insomnia, whereas other variants bring about physiological disturbances that are more specifically related to sleep. It is interesting that there is almost no overlap between genes associated with sleep disorders and those associated with sleep quantity/quality in the general population, which supposedly consists of individuals with no prominent medical conditions. This implies additional complexity in the factors that influence sleep under pathological states.

\section{Future Directions}

Significant advancement has been achieved in understanding the molecular mechanisms for sleep timing regulation, and this likely will lead to therapeutic intervention for body clock regulation in foreseeable future. On the other hand, the mechanism for sleep quality and quantity remains much less understood. Although many theories on sleep functions, such as synaptic regulation, toxin clearance, and energy regeneration, etc, have been proposed, their direct connection to human sleep awaits further validation(DiNuzzo \& Nedergaard, 2017).

Human genetic studies in families and different populations have revealed a plentitude of variants associated with phase, quantity, and/or quality of sleep. However, only a small fraction of these variants have been demonstrated to cause alterations in sleep by animal models that recapitulate, at least in part, the human phenotypes when homologous genes are modified. Molecular genetics in these animal models have been quite powerful for unveiling the underlying mechanisms, and given the evolutionary conservation of sleep regulatory processes, findings in animal studies may be applicable to humans. With advances in sequencing technology, the identification of many more genetic variants associated with sleep traits is expected, and only when they are validated and functionally characterized will they be truly helpful in understanding the regulation of human sleep as well as the 
development of sleep disorders. The advent of the CRISPR/Cas9 system has tremendously facilitated procedures of genetic modification, and much less effort is required nowadays to generate an animal model for a human variant of interest. We are perhaps at the best of times for conducting molecular genetics research to investigate the mysteries of human sleep.

\section{Acknowledgements}

This work was supported by NIH grants NS072360 and NS104782 and by the William Bowes Neurogenetics Fund to Y-HF. and by grants from the Natural Science Foundation of China (31471125 and 31671360) and One Thousand Talents Program of China to LZ.

\section{Abbreviations}

ADA

BTBD9

CKI

CRY1

CRY2

Cul-3

DD

DRD2

DSPD

EEG

EGFR

FABP7

FASP

GWAS

hert

Hertr2

NOS1

NREM sleep

PER2

PER3

REM sleep

RLS adenosine deaminase

BTB(POZ)-domain containing 9

casein kinase I

CRYPTOCHROME1

CRYPTOCHROME2

cullin-3

constant darkness

dopamine receptor D2

delayed sleep phase disorder

electroencephalography

epidermal growth factor receptor

fatty acid-binding protein 7

familial advanced sleep phase

genome-wide association study

hypocretin

hypocretin (orexin) receptor 2

nitric oxide synthase 1

non-rapid eye movement sleep

PERIOD2

PERIOD3

rapid eye movement sleep

restless legs syndrome 


$\begin{array}{ll}\text { SAD } & \text { seasonal affective disorder } \\ \text { SNP } & \text { single nucleotide polymorphism } \\ \text { SWA } & \text { slow wave activity } \\ \text { SWS } & \text { slow wave sleep } \\ \text { VNTR } & \text { variable number tandem repeat }\end{array}$

\section{References}

Allebrandt KV, Amin N, Muller-Myhsok B, Esko T, Teder-Laving M, Azevedo RV, Hayward C, van Mill J, Vogelzangs N, Green EW, Melville SA, Lichtner P, Wichmann HE, Oostra BA, Janssens AC, Campbell H, Wilson JF, Hicks AA, Pramstaller PP, Dogas Z, Rudan I, Merrow M, Penninx B, Kyriacou CP, Metspalu A, van Duijn CM, Meitinger T \& Roenneberg T (2011) A K(ATP) channel gene effect on sleep duration: from genome-wide association studies to function in Drosophila. Mol Psychiatry, 18, 122-132. [PubMed: 22105623]

Allebrandt KV, Teder-Laving M, Cusumano P, Frishman G, Levandovski R, Ruepp A, Hidalgo MPL, Costa R, Metspalu A, Roenneberg T \& De Pitta C (2017) Identifying pathways modulating sleep duration: from genomics to transcriptomics. Sci Rep, 7, 4555. [PubMed: 28676676]

Allen RP, Picchietti D, Hening WA, Trenkwalder C, Walters AS, Montplaisi J, Restless Legs Syndrome D, Epidemiology workshop at the National Institutes of, H. \& International Restless Legs Syndrome Study, G. (2003) Restless legs syndrome: diagnostic criteria, special considerations, and epidemiology. A report from the restless legs syndrome diagnosis and epidemiology workshop at the National Institutes of Health. Sleep Med, 4, 101-119. [PubMed: 14592341]

Bachmann V, Klaus F, Bodenmann S, Schafer N, Brugger P, Huber S, Berger W \& Landolt HP (2012) Functional ADA polymorphism increases sleep depth and reduces vigilant attention in humans. Cereb Cortex, 22, 962-970. [PubMed: 21734253]

Borbely AA, Daan S, Wirz-Justice A \& Deboer T (2016) The two-process model of sleep regulation: a reappraisal. J Sleep Res, 25, 131-143. [PubMed: 26762182]

Cade BE, Gottlieb DJ, Lauderdale DS, Bennett DA, Buchman AS, Buxbaum SG, De Jager PL, Evans DS, Fulop T, Gharib SA, Johnson WC, Kim H, Larkin EK, Lee SK, Lim AS, Punjabi NM, Shin C, Stone KL, Tranah GJ, Weng J, Yaffe K, Zee PC, Patel SR, Zhu X, Redline S \& Saxena R (2016) Common variants in DRD2 are associated with sleep duration: the CARe consortium. Hum Mol Genet, 25, 167-179. [PubMed: 26464489]

Chemelli RM, Willie JT, Sinton CM, Elmquist JK, Scammell T, Lee C, Richardson JA, Williams SC, Xiong Y, Kisanuki Y, Fitch TE, Nakazato M, Hammer RE, Saper CB \& Yanagisawa M (1999) Narcolepsy in orexin knockout mice: molecular genetics of sleep regulation. Cell, 98, 437-451. [PubMed: 10481909]

Cirelli C (2009) The genetic and molecular regulation of sleep: from fruit flies to humans. Nature reviews. Neuroscience, 10, 549-560. [PubMed: 19617891]

Dauvilliers Y, Maret S \& Tafti M (2005) Genetics of normal and pathological sleep in humans. Sleep Med Rev, 9, 91-100. [PubMed: 15737788]

DeAndrade MP, Johnson RL, Jr., Unger EL, Zhang L, van Groen T, Gamble KL \& Li Y (2012) Motor restlessness, sleep disturbances, thermal sensory alterations and elevated serum iron levels in Btbd9 mutant mice. Hum Mol Genet, 21, 3984-3992. [PubMed: 22678064]

DiNuzzo M \& Nedergaard M (2017) Brain energetics during the sleep-wake cycle. Curr Opin Neurobiol, 47, 65-72. [PubMed: 29024871]

Freeman A, Pranski E, Miller RD, Radmard S, Bernhard D, Jinnah HA, Betarbet R, Rye DB \& Sanyal S (2012) Sleep fragmentation and motor restlessness in a Drosophila model of Restless Legs Syndrome. Curr Biol, 22, 1142-1148. [PubMed: 22658601]

Gerstner JR, Perron IJ, Riedy SM, Yoshikawa T, Kadotani H, Owada Y, Van Dongen HPA, Galante RJ, Dickinson K, Yin JCP, Pack AI \& Frank MG (2017) Normal sleep requires the astrocyte brain-type fatty acid binding protein FABP7. Sci Adv, 3, e1602663. [PubMed: 28435883] 
Goel N, Banks S, Mignot E \& Dinges DF (2009) PER3 polymorphism predicts cumulative sleep homeostatic but not neurobehavioral changes to chronic partial sleep deprivation. PLoS One, 4 , e5874. [PubMed: 19516903]

Goldfarb LG, Petersen RB, Tabaton M, Brown P, LeBlanc AC, Montagna P, Cortelli P, Julien J, Vital C, Pendelbury WW \& et al. (1992) Fatal familial insomnia and familial Creutzfeldt-Jakob disease: disease phenotype determined by a DNA polymorphism. Science, 258, 806-808. [PubMed: 1439789]

Hasan S, van der Veen DR, Winsky-Sommerer R, Hogben A, Laing EE, Koentgen F, Dijk DJ \& Archer SN (2014) A human sleep homeostasis phenotype in mice expressing a primate-specific PER3 variable-number tandem-repeat coding-region polymorphism. Faseb J, 28, 2441-2454. [PubMed: 24577121]

He Y, Jones CR, Fujiki N, Xu Y, Guo B, Holder JL, Jr., Rossner MJ, Nishino S \& Fu YH (2009) The transcriptional repressor DEC2 regulates sleep length in mammals. Science, 325, 866-870. [PubMed: 19679812]

Hirano A, Hsu PK, Zhang L, Xing L, McMahon T, Yamazaki M, Ptacek LJ \& Fu YH (2018) DEC2 modulates orexin expression and regulates sleep. Proc Natl Acad Sci U S A, 115, 3434-3439. [PubMed: 29531056]

Hirano A, Shi G, Jones CR, Lipzen A, Pennacchio LA, Xu Y, Hallows WC, McMahon T, Yamazaki M, Ptacek LJ \& Fu YH (2016) A Cryptochrome 2 mutation yields advanced sleep phase in humans. eLife, 5, e16695. [PubMed: 27529127]

Huang ZL, Qu WM, Eguchi N, Chen JF, Schwarzschild MA, Fredholm BB, Urade Y \& Hayaishi O (2005) Adenosine A2A, but not A1, receptors mediate the arousal effect of caffeine. Nat Neurosci, 8, 858-859. [PubMed: 15965471]

Jimenez-Jimenez FJ, Alonso-Navarro H, Martinez C, Zurdo M, Turpin-Fenoll L, Millan-Pascual J, Adeva-Bartolome T, Cubo E, Navacerrada F, Rojo-Sebastian A, Rubio L, Calleja M, Plaza-Nieto JF, Pilo-de-la-Fuente B, Arroyo-Solera M, Garcia-Albea E, Garcia-Martin E \& Agundez JA (2015) Neuronal nitric oxide synthase (nNOS, NOS1) rs693534 and rs7977109 variants and risk for restless legs syndrome. J Neural Transm (Vienna), 122, 819-823. [PubMed: 25300364]

Jones CR, Campbell SS, Zone SE, Cooper F, DeSano A, Murphy PJ, Jones B, Czajkowski L \& Ptacek LJ (1999) Familial advanced sleep-phase syndrome: A short-period circadian rhythm variant in humans. Nat Med, 5, 1062-1065. [PubMed: 10470086]

Li G, Tang H, Wang C, Qi X, Chen J, Chen S \& Ma J (2017) Association of BTBD9 and MAP2K5/ SKOR1 With Restless Legs Syndrome in Chinese Population. Sleep, 40.

Lin L, Faraco J, Li R, Kadotani H, Rogers W, Lin X, Qiu X, de Jong PJ, Nishino S \& Mignot E (1999) The sleep disorder canine narcolepsy is caused by a mutation in the hypocretin (orexin) receptor 2 gene. Cell, 98, 365-376. [PubMed: 10458611]

Medori R, Tritschler HJ, LeBlanc A, Villare F, Manetto V, Chen HY, Xue R, Leal S, Montagna P, Cortelli P \& et al. (1992) Fatal familial insomnia, a prion disease with a mutation at codon 178 of the prion protein gene. N Engl J Med, 326, 444-449. [PubMed: 1346338]

Morairty SR, Dittrich L, Pasumarthi RK, Valladao D, Heiss JE, Gerashchenko D \& Kilduff TS (2013) A role for cortical nNOS/NK1 neurons in coupling homeostatic sleep drive to EEG slow wave activity. Proc Natl Acad Sci U S A, 110, 20272-20277. [PubMed: 24191004]

Mukherjee S, Patel SR, Kales SN, Ayas NT, Strohl KP, Gozal D, Malhotra A \& American Thoracic Society ad hoc Committee on Healthy, S. (2015) An Official American Thoracic Society Statement: The Importance of Healthy Sleep. Recommendations and Future Priorities. Am J Respir Crit Care Med, 191, 1450-1458. [PubMed: 26075423]

Oishi Y, Suzuki Y, Takahashi K, Yonezawa T, Kanda T, Takata Y, Cherasse Y \& Lazarus M (2017) Activation of ventral tegmental area dopamine neurons produces wakefulness through dopamine D2-like receptors in mice. Brain Struct Funct, 222, 2907-2915. [PubMed: 28124114]

Patke A, Murphy PJ, Onat OE, Krieger AC, Ozcelik T, Campbell SS \& Young MW (2017) Mutation of the Human Circadian Clock Gene CRY1 in Familial Delayed Sleep Phase Disorder. Cell, 169, 203-215 e213. [PubMed: 28388406]

Pellegrino R, Kavakli IH, Goel N, Cardinale CJ, Dinges DF, Kuna ST, Maislin G, Van Dongen HP, Tufik S, Hogenesch JB, Hakonarson H \& Pack AI (2014) A novel BHLHE41 variant is associated 
with short sleep and resistance to sleep deprivation in humans. Sleep, 37, 1327-1336. [PubMed: 25083013]

Porkka-Heiskanen T, Strecker RE, Thakkar M, Bjorkum AA, Greene RW \& McCarley RW (1997) Adenosine: a mediator of the sleep-inducing effects of prolonged wakefulness. Science, 276, 1265-1268. [PubMed: 9157887]

Retey JV, Adam M, Honegger E, Khatami R, Luhmann UF, Jung HH, Berger W \& Landolt HP (2005) A functional genetic variation of adenosine deaminase affects the duration and intensity of deep sleep in humans. Proc Natl Acad Sci U S A, 102, 15676-15681. [PubMed: 16221767]

Sehgal A \& Mignot E (2011) Genetics of sleep and sleep disorders. Cell, 146, 194-207. [PubMed: 21784243]

Stefansson H, Rye DB, Hicks A, Petursson H, Ingason A, Thorgeirsson TE, Palsson S, Sigmundsson T, Sigurdsson AP, Eiriksdottir I, Soebech E, Bliwise D, Beck JM, Rosen A, Waddy S, Trotti LM, Iranzo A, Thambisetty M, Hardarson GA, Kristjansson K, Gudmundsson LJ, Thorsteinsdottir U, Kong A, Gulcher JR, Gudbjartsson D \& Stefansson K (2007) A genetic risk factor for periodic limb movements in sleep. N Engl J Med, 357, 639-647. [PubMed: 17634447]

Tafti M, Hor H, Dauvilliers Y, Lammers GJ, Overeem S, Mayer G, Javidi S, Iranzo A, Santamaria J, Peraita-Adrados R, Vicario JL, Arnulf I, Plazzi G, Bayard S, Poli F, Pizza F, Geisler P, Wierzbicka A, Bassetti CL, Mathis J, Lecendreux M, Donjacour CE, van der Heide A, Heinzer R, Haba-Rubio J, Feketeova E, Hogl B, Frauscher B, Beneto A, Khatami R, Canellas F, Pfister C, Scholz S, Billiard M, Baumann CR, Ercilla G, Verduijn W, Claas FH, Dubois V, Nowak J, Eberhard HP, Pradervand S, Hor CN, Testi M, Tiercy JM \& Kutalik Z (2014) DQB1 locus alone explains most of the risk and protection in narcolepsy with cataplexy in Europe. Sleep, 37, 19-25. [PubMed: 24381371]

Tafti M, Lammers GJ, Dauvilliers Y, Overeem S, Mayer G, Nowak J, Pfister C, Dubois V, Eliaou JF, Eberhard HP, Liblau R, Wierzbicka A, Geisler P, Bassetti CL, Mathis J, Lecendreux M, Khatami R, Heinzer R, Haba-Rubio J, Feketeova E, Baumann CR, Kutalik Z \& Tiercy JM (2016) Narcolepsy-Associated HLA Class I Alleles Implicate Cell-Mediated Cytotoxicity. Sleep, 39, 581587. [PubMed: 26518595]

Toh KL, Jones CR, He Y, Eide EJ, Hinz WA, Virshup DM, Ptacek LJ \& Fu YH (2001) An hPer2 phosphorylation site mutation in familial advanced sleep phase syndrome. Science, 291, 1040 1043. [PubMed: 11232563]

Veatch OJ, Keenan BT, Gehrman PR, Malow BA \& Pack AI (2017) Pleiotropic genetic effects influencing sleep and neurological disorders. Lancet Neurol, 16, 158-170. [PubMed: 28102151]

Viola AU, Archer SN, James LM, Groeger JA, Lo JC, Skene DJ, von Schantz M \& Dijk DJ (2007) PER3 polymorphism predicts sleep structure and waking performance. Curr Biol, 17, 613-618. [PubMed: 17346965]

Winkelmann J, Lichtner P, Schormair B, Uhr M, Hauk S, Stiasny-Kolster K, Trenkwalder C, Paulus W, Peglau I, Eisensehr I, Illig T, Wichmann HE, Pfister H, Golic J, Bettecken T, Putz B, Holsboer F, Meitinger T \& Muller-Myhsok B (2008) Variants in the neuronal nitric oxide synthase (nNOS, NOS1) gene are associated with restless legs syndrome. Mov Disord, 23, 350-358. [PubMed: 18058820]

Winkelmann J, Schormair B, Lichtner P, Ripke S, Xiong L, Jalilzadeh S, Fulda S, Putz B, Eckstein G, Hauk S, Trenkwalder C, Zimprich A, Stiasny-Kolster K, Oertel W, Bachmann CG, Paulus W, Peglau I, Eisensehr I, Montplaisir J, Turecki G, Rouleau G, Gieger C, Illig T, Wichmann HE, Holsboer F, Muller-Myhsok B \& Meitinger T (2007) Genome-wide association study of restless legs syndrome identifies common variants in three genomic regions. Nat Genet, 39, 1000-1006. [PubMed: 17637780]

Xu Y, Padiath QS, Shapiro RE, Jones CR, Wu SC, Saigoh N, Saigoh K, Ptacek LJ \& Fu YH (2005) Functional consequences of a CKIdelta mutation causing familial advanced sleep phase syndrome. Nature, 434, 640-644. [PubMed: 15800623]

Xu Y, Toh KL, Jones CR, Shin JY, Fu YH \& Ptacek LJ (2007) Modeling of a human circadian mutation yields insights into clock regulation by PER2. Cell, 128, 59-70. [PubMed: 17218255]

Zhang L, Hirano A, Hsu PK, Jones CR, Sakai N, Okuro M, McMahon T, Yamazaki M, Xu Y, Saigoh N, Saigoh K, Lin ST, Kaasik K, Nishino S, Ptacek LJ \& Fu YH (2016) A PERIOD3 variant causes 
a circadian phenotype and is associated with a seasonal mood trait. Proc Natl Acad Sci U S A, 113, E1536-1544. [PubMed: 26903630] 